\title{
Knowledge Among Women at Reproductive Age About Intrauterine Device in Baquba City
}

\author{
Sahar Qasim Saee ${ }^{1}$, Shahab Ahmed Shakir ${ }^{1}$, Raakad Kamel Saadi ${ }^{1}$ \\ ${ }^{1}$ Scholar Researchers, College of Medicine, Diyala University, Iraq
}

\begin{abstract}
Background: The intrauterine device (IUD) is the most popular form of reversible long-acting contraception in the world which is inserted into a woman>s uterus to prevent pregnancy.

Objectives: To study knowledge among women at reproductive age about intrauterine device in baquba city. Subjects and Method: a cross-sectional study was conducting among women at reproductive age who attended outpatient clinics of Al-Batool Teaching Hospital in Baquba City from the period of the $1^{\text {st }}$ of January to the $30^{\text {th }}$ of June 2020 .

Results: Among 900 women who included in this study, with mean age about $32.2 \pm 8$ years old, about $77.1 \%$ of women respondents had poor knowledge about this method of birth control. The knowledge score was affected significantly by level of education, age, residency, occupation, years of marriage, number of parity as well as the use of IUD. The main source of information is friends and relatives who represent about 93.3\% and a limited role of health care providers. This may cause negative beliefs as well as many myths and rumors about IUD. Conclusion: in this study women were unaware about the basic knowledge of IUDs.
\end{abstract}

Keywords: Knowledge, women, contraception, IUD.

\section{Introduction}

There are various and significant current health issues around the world, but enhancing the quality of maternal health is a significant matter for researchers globally. Family planning in definition is the use of method and practices that allow couples and individuals to anticipate and attain their desired number of children and make the proper spacing and timing of their births. It is obtained through use of contraceptive method and the treatment of involuntary infertility. The ability of a woman to space and limit her pregnancies has a direct impact on her health and well-being as well as on the outcome of each pregnancy ${ }^{[1]}$.

The intrauterine device is the most widely used reversible method of contraception in the world which is reported by the world Health Organization that about 160 million women use IUCDs globally today ${ }^{[2]}$.

It is a method surrounded by misconceptions among women, especially about IUD awareness. In this way, many assume that cancer or infertility may be induced, which is not suggested for young or nulliparous women either, and some show considerable concern or fear regarding the procedure of insertion ${ }^{[3,4]}$. In Iraq, among women who are already using IUDs the fears and misbeliefs about IUD contributed to discontinuation of use in almost half of the women requesting IUD removal ${ }^{[5]}$.

Such perceptions and fears are common; however, research addressing such problems shows that if health providers have accurate and sufficient knowledge about the method, trust in the IUCD may be strengthened, thus increasing the incentive to utilize $\mathrm{it}^{[6]}$.

The IUCDs are very safe, effective, and convenient for postpartum, post-abortion, non-pregnant, and breastfeeding mothers. While it is not protective against Human Immunodeficiency Virus (HIV) transmission, it is safe in HIV infected women. It is equally effective and safe for use in the young and/or nulliparous, older women, and women unable to use hormonal method for preventing pregnancy ${ }^{[7,8]}$.

Intrauterine device users are among the most satisfied women who use contraceptive procedures. 
Contraception satisfaction is correlated with high rates of continuity of use ${ }^{[9,10]}$.

\section{Subject and Method}

A cross-sectional study including 900 women at reproductive age who attended Al-Batool Teaching Hospital in Baquba City, was conducted between the $1^{\text {st }}$ of January to $30^{\text {th }}$ of June 2020. A structured questionnaire was used by the researcher to interview the participants. The first part of the questionnaire included information about socio-demographic characteristics of women: age, residency, level of education, marital age and parity. The second part of the questionnaire contained questions related to women knowledge about IUD and included nine questions. The questions were in the form of (YES, NO and Don't know) questions, where 1 score was put for right answer and 0 score for wrong answer and don't know answer. And the total scores were categorized as: $>50 \%$ (0-4 knowledge score) was poor score, $50-75 \%$
(5-7 knowledge score) was fair and those with more than $75 \%$ (8-9 knowledge score) was very good score.

Statistical Analysis: data was analyzed using statistical package for the social sciences (SPSS version 23) computer software program. Descriptive statistics were presented as frequency tables, variables were expressed as mean \pm standard deviation and categorical variables as numbers and percentages.

\section{Results}

A total of (900) women were enrolled in this study, the mean $\pm \mathrm{SD}$ of women was $32.2 \pm 8$ years. The knowledge score about IUD for the studied women has shown that $77.1 \%(694)$ of women had poor knowledge about IUD with mean score 2.63, fair score was found in $21.8 \%(196)$ of women with mean score 5.75 and only $1.1 \%(10)$ of women had very good knowledge, table 1.

Table 1: Frequency distribution of knowledge score for studied women.

\begin{tabular}{|l|c|c|c|}
\hline Knowledge score & Number & Percentage & Mean \pm SD \\
\hline Poor & 694 & $77.1 \%$ & $2.63 \pm 1$ \\
\hline Fair & 196 & $21.8 \%$ & $5.75 \pm 0.7$ \\
\hline Very good & 10 & $1.1 \%$ & $8.3 \pm 0.4$ \\
\hline Total & 900 & & $3.37 \pm 1.7$ \\
\hline
\end{tabular}

Table 2: The knowledge of participants about various aspects of IUD.

\begin{tabular}{|l|c|c|}
\hline Knowledge questions & Number of right answer & Percentage \\
\hline The types of IUDs & 97 & $10.8 \%$ \\
\hline The rate failure in preventing pregnancy & 369 & $44 \%$ \\
\hline likely to cause an infection & 96 & $10.7 \%$ \\
\hline An IUD can cause infertility & \multicolumn{2}{|c|}{$31334.8 \%$} \\
\hline An IUD can cause Cancer & 233 & $25.9 \%$ \\
\hline An IUD can cause Harmful bleeding time & 517 & $57.4 \%$ \\
\hline Woman after normal vaginal delivery as good candidate for IUD & 871 & $96.8 \%$ \\
\hline Woman after c/s as good candidate for IUD & 435 & $48.3 \%$ \\
\hline A newly married childless couple as good candidate for IUD & 78 & $8.7 \%$ \\
\hline
\end{tabular}

The poor knowledge score percentage decreased with the increase in the age of women from $88.7 \%$ in women with ages less than 20 years to $70.7 \%$ in women with ages $40-49$ years. The poor knowledge score percentage in women who lived in urban areas were higher than the poor knowledge score percentage in women who lived in rural areas (94.3\% VS 69.9\%). With the raise in the education level, there was a decrease in poor knowledge score percentage, table 3 . 
Table 3: Frequency Distribution of knowledge score among socio-demographic characteristics of studied women.

\begin{tabular}{|c|c|c|c|c|c|}
\hline \multirow{2}{*}{\multicolumn{2}{|c|}{ Socio-demographic characteristics }} & \multicolumn{4}{|c|}{ Knowledge score } \\
\hline & & \multirow{2}{*}{$\begin{array}{c}\text { Poor } \\
55(88.7 \%)\end{array}$} & \multirow{2}{*}{$\begin{array}{c}\text { Fair } \\
7(11.3 \%)\end{array}$} & \multirow{2}{*}{$\begin{array}{c}\text { Good } \\
0\end{array}$} & \multirow{2}{*}{$\begin{array}{c}\text { Total } \\
62 \\
\end{array}$} \\
\hline \multirow{4}{*}{ Age } & $<20$ years & & & & \\
\hline & 20-29 years & $232(84.4 \%)$ & $43(15.6 \%)$ & 0 & 275 \\
\hline & 30-39 years & $277(73.1 \%)$ & $98(25.9 \%)$ & $4(1.1 \%)$ & 379 \\
\hline & 40-49 years & $130(70.7 \%)$ & $48(26.1 \%)$ & $6(3.3 \%)$ & 184 \\
\hline Total & & & & & 900 \\
\hline \multirow{2}{*}{ Residency } & Rural & $250(94.3 \%)$ & $15(5.7 \%)$ & 0 & 265 \\
\hline & Urban & $444(69.9 \%)$ & $181(28.5 \%)$ & $10(1.6 \%)$ & 635 \\
\hline Total & & & & & 900 \\
\hline \multirow{5}{*}{ Educational level } & Illiterate & $18(94.7 \%)$ & $1(5.3 \%)$ & 0 & 19 \\
\hline & Read \& write & $53(100 \%)$ & 0 & 0 & 53 \\
\hline & Primary & $136(88.9 \%)$ & $17(11.1 \%)$ & 0 & 153 \\
\hline & Secondary & $300(75.6 \%)$ & $97(24.4 \%)$ & 0 & 397 \\
\hline & Collage \& above & $187(67.3 \%)$ & $81(29.1 \%)$ & $10(3.6 \%)$ & 278 \\
\hline Total & & & & & 900 \\
\hline
\end{tabular}

The poor knowledge score in women with more than five years of marriage was lower than poor knowledge score in women with less than 5 years of marriage. Also, the poor knowledge score in women who had never used IUD (84.9\%) was higher than women who currently used IUD(61.6\%) or past used IUD(75.6\%), Table 4.

Table 4: Frequency Distribution of the knowledge score among obstetrical history of studied women.

\begin{tabular}{|c|c|c|c|c|c|}
\hline \multirow{2}{*}{\multicolumn{2}{|c|}{ Obstetrical history }} & \multicolumn{4}{|c|}{ Knowledge score } \\
\hline & & \multirow{2}{*}{$\begin{array}{c}\text { Poor } \\
171(85.5 \%)\end{array}$} & \multirow{2}{*}{$\begin{array}{c}\text { Fair } \\
29(14.5 \%)\end{array}$} & \multirow{2}{*}{$\begin{array}{c}\text { Good } \\
0\end{array}$} & \multirow{2}{*}{$\begin{array}{c}\text { Total } \\
200\end{array}$} \\
\hline \multirow{3}{*}{$\begin{array}{l}\text { Duration of } \\
\text { marriage }\end{array}$} & $\leq 5$ years & & & & \\
\hline & 6-10 years & $217(73.3 \%)$ & $79(26.7 \%)$ & 0 & 296 \\
\hline & $>10$ years & $306(75.7 \%)$ & $88(21.8 \%)$ & $10(2.5 \%)$ & 404 \\
\hline Total & & & & & 900 \\
\hline \multirow{3}{*}{ Parity } & Para one and two & $230(78.2 \%)$ & $63(21.4 \%)$ & $1(0.3 \%)$ & 294 \\
\hline & Para three and four & $336(76.7 \%)$ & $93(21.2 \%)$ & $9(2.1 \%)$ & 438 \\
\hline & Para five and more & $123(76.2 \%)$ & $40(23.8 \%)$ & 0 & 168 \\
\hline Total & & & & & 900 \\
\hline \multirow{3}{*}{$\begin{array}{l}\text { practice of using } \\
\text { IUD }\end{array}$} & Current user & $132(61.7 \%)$ & $76(35.5 \%)$ & $6(2.8 \%)$ & 214 \\
\hline & Past using & $167(75.6 \%)$ & $50(22.6 \%)$ & $4(1.8 \%)$ & 221 \\
\hline & Never used & $395(84.9 \%)$ & $70(15.1 \%)$ & 0 & 465 \\
\hline Total & & & & & 900 \\
\hline
\end{tabular}

The sources of information about IUD were health care provider in $15.8 \%(143)$, friends represent $93.3 \%(840)$ of sources, mass media represented 15\%(135) of sources and other sources which was self-experiment and readings represent 11.6\%(105), figure 1 . 


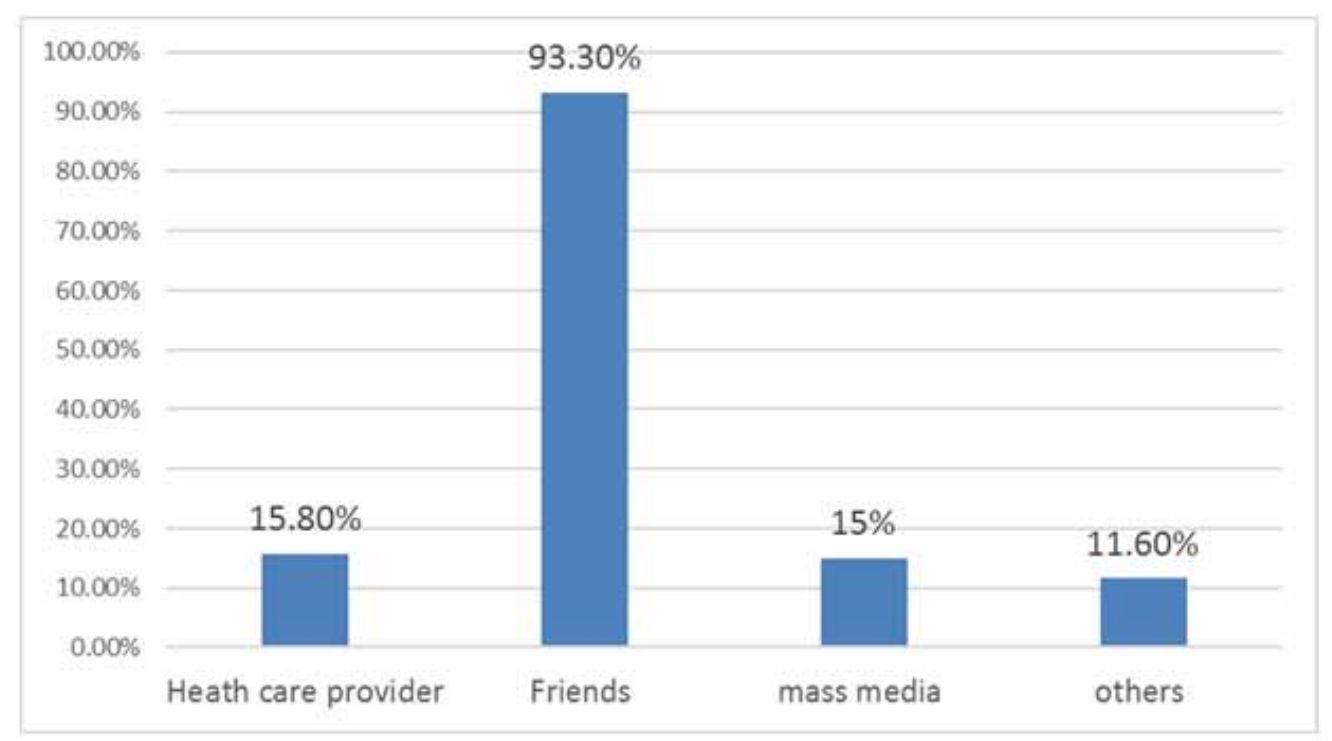

*Note: Some respondents gave more than one response

Figure 1: Source of information about IUD.

\section{Discussion}

The majority of women had inaccurate knowledge about the IUD, for example, $10.8 \%$ of women know about two types of IUD (the majority know about copper IUD and had no knowledge of LNG-IUS) (table 2). This can be attributed to the fact that copper IUD is available free of charge in public sector family planning clinics, while the levonorgestrel-IUS is not available to women accessing these services. This finding agrees with a study done in USA in which nearly all sexually active women know about $\mathrm{Cu}-\mathrm{IUD}$ and $20 \%$ of them know the levonorgestrel-IUS ${ }^{[11]}$. Also $89.3 \%$ of women announced that IUD causes infection (table 2), while infection associated with IUD, only would occur in the first 20 days of insertion and it is due to cervical infection which is not diagnosed during the IUD placement. The World Health Organization found that the risk of development of pelvic inflammatory disease (PID) in women with IUD is the same as or less than the risk of PID in women without IUDs ${ }^{[12]}$. In Iran, a study $50.8 \%$ of the participants had wrong knowledge about IUD in increasing the risk of infection ${ }^{[13]}$. A high percentage of women believed that IUD causes cancer, infertility and heavy bleeding (table 2). This agrees with a study done in USA in 2011 in which the common misperceptions about intrauterine contraception included concerns that intrauterine contraception increases the risk of an ectopic pregnancy, infertility, cancer, or a sexually transmitted infection ${ }^{[14]}$, along with a study in Uganda (2016) where over $40 \%$ of the participants had incorrect information about the IUD in relation to breastfeeding, return to fertility, and protection against STIs. Participants also believed incorrectly that IUDs causes cancer and damages the womb ${ }^{[15]}$.

In addition, women couldn't recognize the appropriate candidate for IUD use (table 2). Where half of women believed that after caesarian section are good candidates for IUD use and the majority believed that nulliparous women are not candidates for IUD use. This can be attributed to the inadequate clients counseling about the IUD, and while this method would be suitable for many women, they avoid using it because they think it is not a good contraceptive option.

However, the general knowledge regarding intrauterine contraceptive devices was limited (table 3), even among IUD users and the existence of myths and rumors about IUD was obvious among the study sample. This may result in discontinuing their IUD use as well as propagate false beliefs amongst their peer groups. This agree with another Iraqi study in Baghdad which is entitled "influence of IUD perceptions on method discontinuation" showed that almost half of the women asked to take the IUD out; fears and false beliefs were the cause of IUD discontinuation ${ }^{[5]}$. Therefore, by training and consulting the clients about possible side effects and how to confront them would remove their concerns.

Interestingly, differences in knowledge about IUD emerged between age groups, duration of 
marriage, and parity history (table 3) (table 4). A possible explanation for that may be due to the idea that most women with increasing age, duration of marriage and parity, had completed their families and they feel that they need more spacing for preserving their health, so they began to seek advice about the safest ways of contraception. This findings is agree with USA study ${ }^{[14]}$ which reported that current age of the mother, years of marriage and parity were significant predictors for knowledge about intrauterine contraception. Residency also reflected differences in knowledge about IUD, suggesting that there are differences in levels of awareness based on women's life state. Also, educational level and occupation showed differences in knowledge about IUD. This agree with Indian study that found a strong association between education $\&$ working status of participants to their awareness about $\mathrm{IUD}^{[16]}$.

The major source of information about IUD were friends and relatives in $93.3 \%$ of the women with secondary minimal role of health care providers \& mass media (figure 1). This is agree with Indian study in $2015^{[16]}$ which has shown that $90 \%$ of information about IUD were from friends, and also agree with a study done in Saudi Arabia 2010 in which the main source of women's knowledge was the family members, media came next. Health workers were reported by small proportion of the participants ${ }^{[17]}$. This highlights the failure of mass media in creating awareness about IUDs and the failure of health care providers in providing contraception knowledge where it should be prioritized as it is a two way communication process and will provide correct and complete information as compared to friends or mass media.

\section{Conclusions}

\section{It is concluded that:}

1. Women in this study were unaware of the basic knowledge regarding IUD.

2. Age of women, residency, educational level, occupation, duration of marriage, parity, history of use of IUDs significantly affect the knowledge scores of the participants regarding IUD.

3. The main persons affecting the decision regarding IUD use were the relatives and friends of respondents.

\section{Conflict of Interest: None}

Funding: Self

Ethical Clearance: Not required

\section{References:}

1. WHO, family planning bulletin, Fact sheet $\mathrm{N}^{\circ} 351$, Updated May 2013. accessed athttp://www.who. int/topics/family_planning/en/.

2. d>Arcangues C. Worldwide use of intrauterine devices for contraception; 2007. 75(6):S2-S7.

3. Carvalho MLO, Schor N. Reasons why sterilized women refused reversive contraceptive method. Rev Saúde Pública; 2005. 39(5):788-94.

4. Silva-Filho AL, Lira J, Rocha ALL, Ferreira MCF, Lamaita RM, Cândido EB. Non-hormonal and hormonal intrauterine contraception: survey of patients' perceptions in four Latin American countries. Eur J Contracept Reproduct Health Care; 2016. 21(3):213-9

5. Alnakash AH. Influence of IUD perceptions on method discontinuation. Contraception; 2008. 78(4):290-3.

6. Gomez AM, Hartofelis EC, Finlayson S, Clark JB. Do knowledge and attitudes regarding intrauterine devices predict interest in their use? Women's Health Issue; 2015. 25(4) 359-65.

7. World Health Organization. Medical Eligibility Criteria for Contraceptive Use. 5th ed. World Health Organization; 2015.

8. Taye A, Woldie M, Sinaga M. Predictors of long acting reversible contraceptive use among married women visiting health facilities in Jimma Town. J Women's Health Care. 2014;4:1.

9. Werth SR, Secura GM, Broughton HO, Jones ME, Dickey V, Peipert JF. Contraceptive continuation in Hispanic women. Am J Obstet Gynecol; 2015. 212(3):312.e1-8.

10. Borges ALV, Santos OA, Araújo KS, Gonçalves RFS, Santa Rosa PLF, Nascimento NC. Satisfaction with the use of contraceptive method among women from primary health care services in the city of São Paulo, Brazil. Rev Bras Saúde Mater Infantil; 2017. 17(4):749-56.

11. Stanwood NL, Bradley KA. Young pregnant women's knowledge of modern intrauterine devices. Obstetrics \& Gynecology; 2006.108(6):1417-22.

12. Grimes DA. Intrauterine device and upper-genitaltract infection. The Lancet; 2000. 356(9234):10139. 
13. Ehsanpour S, Mohammadifard M, Shahidi S, Nekouyi NS. A comparative study on attitude of contraceptive method users towards common contraceptive method. Iranian journal of nursing and midwifery research; 2010. 15(Suppl1):363.

14. Hladky KJ, Allsworth JE, Madden T, Secura GM, Peipert JF. Women's knowledge about intrauterine contraception. Obstetrics and gynecology; 2011. 117(1):48.

15. Twesigye R, Buyungo P, Kaula H, Buwembo D. Ugandan women's view of the IUD: generally favorable but many have misperceptions about health risks. Global Health: Science and Practice; 2016. 4(Supplement 2):S73-S82.

16. Jogiya PD, Lodhiya KK, Chavada P. Assessment of awareness and beliefs regarding intra uterine device amongst its former users attending tertiary care centre in Gujarat. International Journal of Medical Research \& Health Sciences; 2015. 4(2):332-8.

17. Al Sheeha M. Awareness and use of contraceptives among saudi women attending primary care centers in Al-qassim, saudi arabia. International journal of health sciences; 2010. 4(1):11-21. 